\title{
PENGETAHUAN IBU NIFAS TENTANG KUNJUNGAN ULANG MASA NIFAS DI PUSKESMAS TEPUS 1 KABUPATEN GUNUNGKIDUL
}

\author{
Ekawati $^{1^{*}}$, Haniah $^{2}$ \\ 1,2 Program Studi Kebidanan Stikes Jenderal Achmad Yani Yogyakarta, Jl. Ringroad Barat \\ Ambarketawang, Gamping, Sleman.Telp.(02744342000),Email: ekawati_1412@yahoo.com
}

\begin{abstract}
Background: The causes of Maternal Mortality Rate (MMR) in Indonesia are bleeding (30.3\%), hypertensive disorder during pregnancy (27.1\%), infection (7.3\%), obstructed (1.8\%) and abortion (1.6\%). Bleeding occurs in the postpartum period which is started after delivering placenta and ended when the the womb organs recovered as before pregnant. The length of postpartum period is about 6 weeks. During postpartum period, there are several re-visit to heath provider such as; KF 1 (first postpartum visit) is a visit on 6 hours to day 3 rd after delivering, KF 2 (Second postpartum visit) is a visit on day 4th to 28th after delivering, and KF 3 (third postpartum visit) is a visit on day 29th-42nd after delivering.

Objective: This study aimed to describe the knowledge level of postpartum mother about visitation during childbirth.

Method: This study was a descriptive quantitative research with cross sectional design. The number of sample was 30 respondents. The data were taken using primary data and questionnaires.

Result: The postpartum mother who do postpartum visits in Puskesmas Tepus 1 Gunung in the age of 20-35 years category was 19 respondents $(63.3 \%)$. A number of 13 respondents $(43.3 \%)$ had secondary school, 19 respondents (63.3\%) were housewife and 18 respondents $(60 \%)$ had $2-3$ children. The result of postpartum revisit showed that 13 respondents (43.3\%) made KF1, 12 respondents (40\%) made KF 2, and 11 respondents $(36.7 \%)$ made KF 3.
\end{abstract}

Conclusion: The knowledge level of postpartum revisit in Puskesmas Tepus 1 Gunung was mostly in adequate category.

Key word: Postpartum Mother Knowledge, Postpartum Visits

\section{PENDAHULUAN}

Masa nifas yaitu dimulai setelah kelahiran plasenta dan berakhirnya ketika alat-alat kandungan kembali seperti keadaan sebelum hamil, masa nifas berlangsung selama 6 minggu. Pada masa nifas ada beberapa kunjungan yaitu, kunjungan KF 1 (6 jam-3 hari setelah persalinan), KF 2 (hari ke 4-28 setelah persalinan), KF 3 (hari ke 29-42 setelah persalinan). Tujuan kunjungan masa nifas untuk mengetahui kondisi kesehatan ibu dan bayi selama masa nifas. ${ }^{1}$
Kunjungan nifas menggambarkan jangkauan dan kualitas pelayanan kesehatan terhadap ibu, mulai 6 jam-42 hari setelah melahirkan. Pada tahun 2014 ibu nifas yang telah memperoleh pelayanan minimal 3 kali sesuai distribusi waktu dan sesuai standar (KF3) mencapai 92\%. Dari hasil capaian tersebut, terlihat kesenjangan yang cukup jauh antara capaian persalinan oleh tenaga kesehatan dengan kunjungan nifas lengkap, dapat dilihat ibu nifas yang tidak melakukan kunjungan ulang masa nifas, walaupun sudah melahirkan dengan 
bantuan tenaga kesehatan. ${ }^{1}$

Berdasarkan capaian cakupan kunjungan masa nifas (KF3) di Indonesia yang tertinggi yaitu provinsi DKI Jakarta (94,64\%), Yogyakarta $(94,54 \%)$, dan Sumatra Utara $(94,15 \%)$. Sehingga dapat disimpulkan bahwa kunjungan nifas di tiga provinsi tersebut sudah baik. Hal tersebut menunjukkan bahwa sebagian besar ibu nifas sudah melakukan kunjungan nifas di tenaga kesehatan. Indikator tersebut secara nasional sudah mengambarkan bahwa kesadaran ibu nifas tentang kunjungan ulang nifas sudah baik (Profil kesehatan Indonesia, 2014). ${ }^{2}$

Proporsi pelayanan kesehatan ibu nifas di Yogyakarta yang mendapat pelayanan kesehatan masa nifas lengkap yaitu, Sleman $(57,4 \%)$, kota Yogyakarta (53,6\%), Bantul (40,8\%), Kulon Progo $(33,1 \%)$, Gunungkidul (27,5\%), dari data tersebut maka yang mempunyai cakupan paling rendah yaitu Kabupaten Gunungkidul.

(2) Cakupan kunjungan ulang nifas terendah di Puskesmas Tepus 1 yaitu (71,4\%), sedangkan tertinggi di Puskesmas Nglipar 1 yaitu (100\%). Dari data tersebut, maka peneliti akan melakukan penelitian di Puskesmas Tepus 1, karena cakupan kunjungan ulang nifas yang masih sangat rendah dibandingkan dengan puskesmas lain yang berada di Kabupaten Gunung Kidul. Berdasarkan studi pendahuluan yang dilakukan pada tanggal 7 Maret 2016, peneliti mendapatkan data dari ruang
Kesehatan lbu dan Anak (KIA) Puskesmas Tepus 1 kecamatan Tepus kabupaten Gunungkidul, dalam 1 bulan terakhir dengan jumlah ibu ibu nifas 62 orang yang melakukan kunjungan ulang KF 1 yaitu $(19,2 \%)$, KF 2 (14,8\%), sedangkan pada KF 3 hanya (4,3\%), dari data Puskesmas Tepus 1 menunjukkan bahwa kunjungan KF 2 dan KF 3 tidak sesuai dengan kunjungan KF1 karena 7 orang yang tidak berdomisili di Puskesmas Tepus 1, Sehingga kunjungan ulang masa nifas di Puskesmas Tepus 1 belum sesuai dengan standar program kebijakan pemerintah tentang kunjungan ulang masa nifas. Berdasarkan uraian tersebut maka penting diteliti sehingga penulis ingin mengambil penelitian dengan judul Studi deskriptif pengetahuan ibu nifas tentang kunjungan ulang masa nifas di Puskesmas Tepus 1 kecamatan Tepus Gunungkidul pada tahun 2016.

\section{BAHAN DAN CARA PENELITIAN}

Jenis penelitian ini adalah merupakan penelitian deskriptif. Populasi dalam penelitian adalah semua ibu nifas dengan jumlah 30 ibu nifas yang berada di Puskesmas Tepus 1 Gunungkidul.

Teknik pengambilan sampel dengan total sampling dengan jumlah 30 ibu nifas. Total sampling adalah teknik pengambilan sampel di mana jumlah sampel sama dengan populasi. (3) Analisis data yang digunakan yaitu menggunakan analisis univariat. 


\section{HASIL DAN PEMBAHASAN}

Tabel 1. Distribusi frekuensi di Puskesmas Tepus 1 Gunungkidul Tahun 2016

\begin{tabular}{llcc}
\hline No & Karakteristik & $\mathbf{f}$ & $\%$ \\
\hline 1. & Umur & & \\
& a. $<20$ tahun & 6 & 20 \\
& b. $20-35$ tahun & 19 & 63,3 \\
& c. $>35$ tahun & 5 & 16,7
\end{tabular}

2. Pendidikan ibu

$\begin{array}{lcc}\text { a.SD } & 7 & 23,3 \\ \text { b.SMP } & 13 & 43,3 \\ \text { c.SMA } & 10 & 33,3\end{array}$

3. Pekerjaan ibu

$\begin{array}{lcc}\text { a.IRT } & 19 & 63,3 \\ \text { b.Petani } & 3 & 10 \\ \text { c.Pedagang } & 4 & 13,3 \\ \text { d.Nelayan } & 2 & 6,7 \\ \text { e.Buruh } & 2 & 6,7\end{array}$

4. Jumlah anak

\begin{tabular}{lcc} 
a.1 & 12 & 40 \\
b.2-3 & 18 & 60 \\
\hline Jumlah & 30 & 100
\end{tabular}

Sumber data primer, 2016

Berdasarkan table 1 mayoritas ibu nifas berusia 20-35 tahun sebanyak 63,3\%, pendidikan SMP 43,3\%, pekerjaan IRT $63,3 \%$, dan jumlah anak $2-3$ sebanyak $60 \%$.

Berdasarkan tabel 2 di bawah terkait pengetahuan ibu nifas tentang masanifas secara umum dalam kategori baik sebanyak $60 \%$, KF 1 kategori baik 43,3\%, KF 2 kategori cukup 40\%, dan KF 3 kategori kurang $36,7 \%$.

Tabel 2. Distribusi frekuensi pengetahuan ibu nifas tentang kunjungan ulang masa nifas di Puskesmas Tepus 1 Gunungkidul Tahun 2016 No Pengetahuan $\quad f \quad(\%)$

\begin{tabular}{|c|c|c|c|}
\hline & $\begin{array}{l}\text { tentang kunjungan } \\
\text { ulang nifas }\end{array}$ & & \\
\hline \multirow{4}{*}{1.} & Masa Nifas & & \\
\hline & Baik & 18 & 60 \\
\hline & Cukup & 10 & 33,3 \\
\hline & Kurang & 2 & 6,7 \\
\hline \multirow[t]{4}{*}{2.} & $\begin{array}{l}\text { Kunjungan Ulang } \\
\text { nifas } 1 \text { (KF 1) }\end{array}$ & & \\
\hline & Baik & 13 & 43,3 \\
\hline & Cukup & 12 & 40 \\
\hline & Kurang & 5 & 16,7 \\
\hline \multirow[t]{4}{*}{3.} & $\begin{array}{l}\text { Kunjungan Ulang } \\
\text { Nifas } 2 \text { (KF 2) }\end{array}$ & & \\
\hline & Baik & 11 & 36,7 \\
\hline & Cukup & 12 & 40 \\
\hline & Kurang & 7 & 23,3 \\
\hline \multirow[t]{5}{*}{4.} & $\begin{array}{l}\text { Kunjungan Ulang } \\
\text { Nifas } 3 \text { (KF 3) }\end{array}$ & & \\
\hline & Baik & 9 & 30 \\
\hline & Cukup & 10 & 33,3 \\
\hline & Kurang & 11 & 36,7 \\
\hline & Jumlah & 30 & 100 \\
\hline
\end{tabular}

Tabel 3. Distribusi frekuensi pengetahuan ibu nifas tentang kunjungan ulang masa nifas secara umum di Puskesmas Tepus 1 Gunungkidul Tahun 2016

Pengetahuan $\quad$ f $\%$

kunjungan ulang nifas

\begin{tabular}{ccc}
\hline Baik & 11 & 36,7 \\
Cukup & 12 & 40 \\
Kurang & 7 & 23,3 \\
\hline Jumlah & 30 & 100 \\
\hline \multicolumn{2}{l}{ Sumber data primer, 2016 }
\end{tabular}

Pengetahuan ibu nifas tentang kunjungan ulang masa nifas di Puskesmas Tepus 1 Gunungkidul secara umum adalah cukup (40\%). Pengetahuan merupakan hasil tahu dari tahu sebagai akibat proses penginderaan terhadap obyek tertentu melalui panca indera dan sebagian besar pengetahuan manusia diperoleh melalui mata 
dan telinga. ${ }^{4}$ Pengetahuan memungkinkan seseorang untuk dapat memecahkan masalah yang dihadapinya di mana pengetahuan tersebut diperoleh dari pengalaman langsung maupun melalui pengalaman orang lain. Pengetahuan atau kognitif merupakan dominan yang sangat penting dalam membentuk tindakan seseorang, berdasarkan pengalaman dan penelitian ternyata perilaku yang didasari pengetahuan akan lebih tahan lama dari pada memiliki pengetahuan cukup tentang kunjungan ulang masa nifas yang berbagai upaya untuk mencegah terjadinya komplikasi pada ibu nifas.

Pengetahuan ibu nifas dapat dipengaruhi oleh faktor usia yang mayoritas berada dalam kelompok usia produktif 20-35 tahun sebanyak 19 responden (63,3\%). Semakin cukup umur, maka tingkat kematangan seseorang akan bertambah dan pengalaman serta pengetahuannya semakin luas. ${ }^{5}$

Faktor lain yang memengaruhi pengetahuan ibu nifas adalah tingkat pendidikan yang mayoritas cukup yaitu SMP sebanyak 13 responden (43,3\%). Berdasarkan hasil wawancara menyatakan hal ini disebabkan oleh sosial ekonomi masyarakat sehingga sebagian besar hanya menempuh pendidikan sampai SMP saja. Masyarakat beranggapan bahwa pendidikan SMP sudah tinggi, sehingga mereka tidak terlalu mementingkannya, tingginya tingkat pendidikan seseorang dapat digunakan modal untuk menerima informasi sehingga dapat memengaruhi pengetahuan seseorang. Tingkat pendidikan juga turut menentukan mudah tidaknya seseorang menyerap dan memahami pengetahuan yang mereka peroleh, pada umumnya semakin tinggi pendidikan seseorang semakin baik juga pengetahuannya sehingga pengetahuan tersebut dapat diaplikasikan dalam hidupnya. ${ }^{6}$

Dilihat dari pekerjaan ibu nifas mayoritas ibu tidak bekerja dengan jumlah 19 responden (63,3\%), masyarakat setempat beranggapan bahwa pekerjaan adalah hal yang menyita waktu, sehingga ibu tidak terlalu mementingkan pekerjaan. Hal ini dapat memengaruhi pengetahuan kunjungan ulang masa nifas. Akan tetapi, dengan perkembangan teknologi informasi dan komunikasi khususnya berbasis internet, memudahkan seseorang memperoleh informasi dan pengetahuan sehingga mereka menganggap pekerjaan bukanlah hal yang penting bagi ibu nifas di Gunungkidul. Pengalaman merupakan sumber pengetahuan, pengalaman yang baik akan meninggalkan kesan yang mendalam bagi jiwa seseorang dan akan bersifat positif dalam kehidupannya. ${ }^{7}$

Sebagian besar ibu mempunyai jumlah anak 2-3 (60\%), jumlah anak juga dapat memengaruhi pengetahuan seseorang khususnya tentang kunjungan ulang masa nifas, karena sudah memiliki pengalaman masa nifas. Pengalaman 
merupakan sumber pengetahuan sehingga pengalaman dapat dijadikan sebagai modal seseorang untuk mengetahui pengetahuan khususnya tentang kunjungan ulang masa nifas. $^{7}$

Tingkat pengetahuan kunjungan ulang nifas tentang pengertian masa nifas sebagian besar memiliki pengetahuan dalam kategori baik sebanyak 18 responden (60\%). Salah satu faktor yang memengaruhi pengetahuan tentang masa nifas adalah umur. Semakin tua seseorang maka akan mempunyai kesempatan dan waktu yang lebih lama dalam mendapatkan informasi dan pengetahuan tentang pengertian masa nifas. Dengan demikian semakin tua umur responden maka tingkat pengetahuan responden tentang pengertian kunjungan ulang masa nifas semakin baik. Umur sangat memengaruhi dalam meningkatkan pengetahuan karena pengetahuan mental yang terus bertambah dan diiringi bertambahnya umur, maka kemampuan menerima informasi makin menurun. ${ }^{5}$

Tingkat pengetahuan kunjungan ulang nifas tentang kunjungan ulang nifas 1 (KF 1) sebagian besar memiliki pengetahuan dalam kategori baik sebanyak 13 responden (43,3\%). Hal ini dapat dipengaruhi oleh faktor pendidikan karena semakin tinggi pendidikan seseorang, maka semakin mudah menerima informasi sehingga semakin banyak pengetahuan yang dimiliki. Responden yang berpendidikan tinggi akan mudah menyerap informasi, sehingga pengetahuan dan pengalaman yang dimiliki lebih tinggi namun, sebaliknya responden yang berpendidikan rendah akan mengalami hambatan dalam penyerapan informasi sehingga pengetahuan dan pengalaman yang dimiliki lebih rendah yang berdampak pada kehidupannya. Hal ini sejalan dengan pendapat Notoatmodjo tingginya tingkat pendidikan seseorang dapat digunakan modal untuk menerima informasi sehingga dapat mempengaruhi pengetahuan seseorang. Tingkat pendidikan turut menentukan mudah tidaknya seseorang menyerap dan memahami pengetahuan yang mereka peroleh, pada umumnya semakin tinggi pendidikan seseorang semakin baik juga pengetahuannya. ${ }^{6}$

Tingkat pengetahuan kunjungan ulang nifas tentang kunjungan ulang nifas 2 (KF 2) sebagian besar memiliki pengetahuan cukup (40\%). Pengetahuan dapat berpengaruh terhadap pekerjaan ibu. Hasll penelitian ini didapatkan sebagian besar responden tidak bekerja (IRT) karena bekerja merupakan kegiatan yang menyita waktu. Bekerja bagi ibu akan memengaruhi pada kehidupannya sehingga ibu banyak yang tidak mendapatkan informasi. Hal ini tidak sesuai dengan pendapat Soekanto bahwa salah satu faktor pembentuk pengetahuan seseorang adalah lingkungan sekitar termasuk didalamnya lingkungan kerja. Akan tetapi, seiring dengan perkembangan teknologi informasi dan komunikasi khususnya berbasis internet, memudahkan seseorang untuk memperoleh informasi dan 
sumber pengetahuan tanpa harus dibatasi oleh ruang dan waktu. ${ }^{8}$

Tingkat pengetahuan kunjungan ulang nifas tentang kunjungan ulang nifas 3 (KF 3 ) sebagian besar memiliki pengetahuan kurang $(36,7$ \%). Hal ini disebabkan karena mayoritas ibu nifas tersebut tidak berdomisili di daerah Gunungkidul melainkan di luar kota sehingga, ibu nifas tersebut melakukan kunjungan ulang nifas ke tenaga kesehatan lainnya. Multipara merupakan wanita yang telah melahirkan dua atau tiga anak. Seseorang mempunyai riwayat reproduksi yang berkaitan dengan jumlah kehamilannya. Wanita yang sudah memiliki dua sampai 3 anak pada umumnya sudah mengetahui informasi dan pengalaman tentang kesehatan salah satunya tentang kunjungan ulang masa nifas. ${ }^{9}$

\section{KESIMPULAN}

Pengetahuan ibu nifas tentang kunjungan ulang masa nifas di Puskesmas Tepus 1 Gunungkidul sebagian besar dalam kategori cukup, sehingga tenaga kesehatan harus meningkatkan pendidikan kesehatan tentang tentang masa nifas maupun melakukan kunjungan ke rumah selama masa nifas.

\section{KEPUSTAKAAN}

1. Prawirohardjo, S. Asuhan Kebidanan Masa Nifas. Jakarta: PT Bina Pustaka. 2006

2. Profil Kesehatan Indonesia. Cakupan Kunjungan Ulang. Akses 21 April 2016 pukul 14.00 WIB. 2014

3. Sugiyono. Metode Penelitian Kuantitatif Kualitatif dan $R$ dan $D$. Bandung: Alfabeta. 2007

4. Notoatmodjo. S. Metodologi Penelitian Kesehatan, Jakarta: Rineka Cipta. 2012

5. Notoatmodjo. S. Metodologi Penelitian Kesehatan, Jakarta: Rineka Cipta. 2005

6. Notoatmodjo. S. Metodologi Penelitian Kesehatan, Jakarta: Rineka Cipta. 2007

7. Notoatmodjo. S. Metodologi Penelitian Kesehatan, Jakarta: Rineka Cipta. 2010

8. Muflikhatul dan Tarmi. Hubungan Pengetahuan Ibu Nifas Dengan Kepatuhan Kunjungan Masa Nifas Di Bpm Ny. Subiyanah, Sst Desa Parengan Kecamatan Madurankabupaten Lamongan. Jurnal Kebidanan Vol.02, No.XVIII, Juni 2014.

9. Manuaba. Kesehatan Reproduksi Wanita, Jakarta EGC. 2009 